\title{
Root hair growth: it's a one way street
} Amelie Mendrinna ${ }^{1}$, and Staffan Persson ${ }^{1,2 *}$

\author{
Addresses: ${ }^{1}$ Max-Planck Institute for Molecular Plant Physiology, Am Muehlenberg 1, 14476 Potsdam, Germany; ${ }^{2}$ ARC Centre of Excellence in \\ Plant Cell Walls, School of Botany, University of Melbourne, Parkville 3010, Victoria, Australia \\ * Corresponding author: Staffan Persson (Staffan.Persson@unimelb.au.edu) \\ Fl000Prime Reports 2015, 7:23 (doi:10.12703/P7-23) \\ All FI000Prime Reports articles are distributed under the terms of the Creative Commons Attribution-Non Commercial License \\ (http://creativecommons.org/licenses/by-nc/3.0/legalcode), which permits non-commercial use, distribution, and reproduction in any medium, \\ provided the original work is properly cited. \\ The electronic version of this article is the complete one and can be found at: http://fl $000 . c o m / p r i m e / r e p o r t s / b / 7 / 23$
}

\begin{abstract}
Over the last few decades, our understanding of directed cell growth in different organisms has substantially improved. Tip-growing cells in plants elongate rapidly via targeted deposition of cell wall and membrane material at the cell apex, and use turgor pressure as a driving force for expansion. This type of polar growth requires a high degree of coordination between a plethora of cellular and extracellular components and compounds, including calcium dynamics, apoplastic reactive oxygen species and $\mathrm{pH}$, the cytoskeleton, and vesicular trafficking. In this review, we attempt to outline and summarize the factors that control root hair growth and how they work together as a team.
\end{abstract}

\section{Introduction}

Filamentous cells represent an important advance in cellular growth and are also important devices for the colonization of land by fungi and plants [1]. For example, filamentous growth in the form of aseptate hyphae evolved as an excellent tool for exploring dry soils [2]. This innovation also enabled the fungi to establish close relationships with land plants, for example, through symbiotic relationships that resemble arbuscular mycorrhizal associations today. In arbuscular mycorrhiza, tip-growing fungal hyphae rapidly enter plant root tissue to establish a mutually beneficial relationship [3]. The first tip-growing cells in land-plants arose about 450 million years ago in bryophytes, which used filamentous rhizoids for anchoring themselves to the soil [1]. In plants today, two types of tip-growing cells dominate; pollen tubes and root hairs. While pollen tubes provided for water-independent propagation of species [4], root hairs bestowed an increase in root surface area that could be used to increase nutrient uptake and better anchor plants in the soil. Root hairs and pollen tubes are filamentous cells that grow unidirectionally by depositing flexible cell wall material at one site of the cell and exploiting turgor pressure as the driving force for elongation; a process also referred to as tip growth (Figure 1).

Although these tip-growing systems are very similar, they also display differences in their growth-related molecular machineries. In view of the fact that soil nutrient availability, water accessibility and soil condition are strongly affected by climate change $[5,6]$, the study of root hair tip growth is a timely topic to help us to understand and improve plant growth and will therefore be the main focus of this review.

Root hair growth: from the inside to the outside While delicate, root hairs are excellent experimental model systems for polarized cell growth. They reach growth rates of typically $1 \mu \mathrm{m} \mathrm{min}{ }^{-1}$ or more [7] without losing cell wall integrity. This implies an extremely efficient system for delivering and modifying membrane and cell wall material at the tip apex. This system will therefore need to be highly coordinated, and involves a tip-derived calcium gradient, cytoskeleton dynamics, delivery of new cell wall material via vesicle trafficking, regulation of extracellular $\mathrm{pH}$, and production of reactive oxygen species (ROS). How these players are geared to 
Figure I. Regulators of directed cell growth in root hairs and pollen tubes
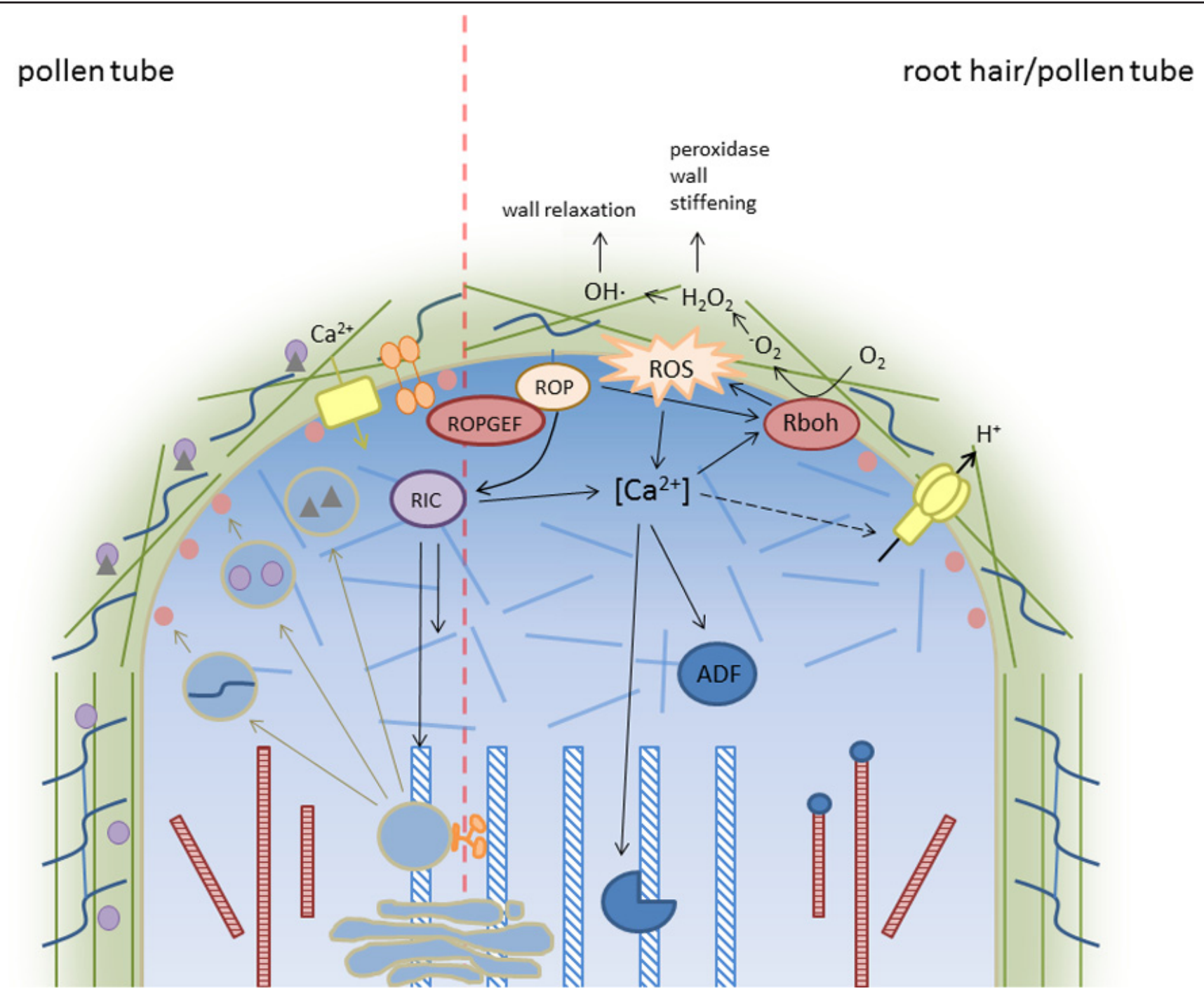

Root hair and pollen tube tip growth include a variety of cellular components and compounds that work in concert. The intracellular calcium concentration plays a central role in plant tip growth, and regulates actin dynamics via actin interacting proteins, such as villin and ADF. These proteins are likely involved in the organization of the actin cytoskeleton at different sites in the root hair. Microtubules are located net axially, i.e. along the shank, and reach into the subapical region of the root hair. Their dynamic behaviour is regulated by the microtubule plus end-tracking protein ARKI and is important for maintenance of polarity and growth direction. Calcium also activates respiratory burst oxidase homologues (Rbohs). These produce $\mathrm{ROS}_{(}\left(\mathrm{H}_{2} \mathrm{O}_{2}\right.$ and $\mathrm{OH}$ ) which mediate cell wall relaxation and peroxidase-mediated wall stiffening. ROS may also partake in a positive feedback loop by activating calcium influx from the apoplast into the cytosol. The channels responsible for calcium influx are not known in root hairs but, in pollen tubes, CNGC and GLR channels have been identified. Furthermore, calcium seems to influence extracellular $\mathrm{pH}$ (possibly via $\mathrm{H}^{+}$-ATPases), which contributes to changes in cell wall structure during growth. Cellulose microfibrils are short and randomly oritientated in the cell wall of the growing tip, whereas a well ordered second layer of cellulose microfibrils occurs in the shank. This organization promotes dynamic cell wall extension exclusively at the tip. In pollen tubes PMEs mediate the crosslinking of pectins in the shank and remain inactive at the tip after inactivation through PMEls. Pectin, PMEs and PMEls are delivered from the Golgi/trans Golgi network to the plasma membrane of the pollen tube tip via actin-dependent vesicle trafficking. Vesicles are spacially directed by the distribution of Pls in the plasma membrane and are transported along the actin cytoskeleton via motor proteins. Tip growth is regulated by several plasma membrane receptor-like kinases, for example, FERONIA and ANXUR. FERONIA is known to regulate ROP signaling pathways via interaction with ROP guanine nucleutide exchange factors. Important ROP effectors in pollen tubes are RICs that directly influence tip growth by interaction with bundled and fine F-actin and modulation of intracellular calcium concentrations. Abbreviations: ADF, actin depolymerizing factor; ARKI, armadillo-repeat kinesin I; CNGC, cyclic nucleotide-gated channel; GLR, glutamate receptor-like; PI, inositol phosphate; PME, pectin-methyl-esterase; PMEI, PME inhibitor; RIC, Rop-interactive CRIB motif-containing; ROP, Rho of plant GTPase; ROS, reactive oxygen species. 
each other is only partly known, but recent studies have made great progress leading to a better understanding of the coordination.

\section{Intracellular calcium and ROS}

Two of the major signal transducers for root hair growth and function are $\mathrm{Ca}^{2+}$ and ROS (Figure 1). Calcium is a crucial and general regulator of plant cell growth and development, and is perhaps the most important factor for maintenance of tip growth where it is distributed as a continuous gradient in the cytosol, with the highest concentration close to the tip apex [8]. Furthermore, the cytosolic $\mathrm{Ca}^{2+}$ concentration displays periodic cycling that follows the rate of growth of the tip. This cycling appears to be coordinated with a rise and decline of both apoplastic $\mathrm{pH}$ and ROS production. These findings suggest that changes in $\mathrm{Ca}^{2+}$ concentrations might regulate growth by the activation of ROS production, and by increasing the $\mathrm{pH}$, at the cell surface [9]. The production of cell surface ROS in turn activates $\mathrm{Ca}^{2+}$ influx into the cell and thereby completes a positive feedback loop [10,11].

The increase in cytosolic $\mathrm{Ca}^{2+}$ is typically facilitated by membrane located $\mathrm{Ca}^{2+}$ channels. While the identity of these channels are not known in root hairs, cyclic nucleotide-gated (CNGC), and glutamate receptor-like (GLR), channels were identified as $\mathrm{Ca}^{2+}$ influx channels [2-4] in pollen tubes, and perhaps a similar scenario could be envisioned during root hair growth. The function of the fluctuations in intracellular $\mathrm{Ca}^{2+}$ may modulate components important for tip growth, such as cytoskeletonorganizing factors, and ROS and $\mathrm{pH}$ homeostasis as alluded to above. However, it may also alter the apoplastic $\mathrm{Ca}^{2+}$ levels that can influence changes in the cell wall.

\section{Cytoskeleton and vesicles}

In tip growing cells, the actin cytoskeleton is typically organized as thick actin bundles that run in parallel with the root hair shank supporting an inverse fountain flow of cytoplasmic streaming, and as fine filamentous structures at the apex of the tip that keep this region free of larger cell organelles [5-8]. The organization of the actin cytoskeleton is controlled by a variety of actin binding proteins (ABPs), which aid in nucleation, depolymerisation and cross-linking of the actin cytoskeleton [8]. The activity of some of these components may be influenced by $\mathrm{Ca}^{2+}$. For example, $\mathrm{Ca}^{2+}$ may influence actin depolymerizing factor (ADF) in maize that can increase actin turnover by severing actin filaments [9], and villins that can influence the bundling of actin. This implicates $\mathrm{Ca}^{2+}$ fluxes and ABPs in the actin organization in root hairs.

The role of the actin cytoskeleton as a scaffold for polarized membrane trafficking is well established in root hairs. In particular, new membrane and cell wall material must be delivered to the tip apex to support the rapid growth. The cell wall material is engulfed in vesicles that move along the actin cytoskeleton via motor proteins. Two recently characterized motor proteins of the MYOSIN XI family that function in actin-dependent transport of cell organelles, vesicles and protein complexes $[10,11]$, are required for normal actin dynamics and fast root hair growth $[12,13]$.

Vesicle secretion can also be controlled by other factors, including Rab GTPases [14] and inositol phosphates (PIs). For example, PI-4P and PI-4,5P 2 accumulate in the plasma membrane at the root hair apex where they might orchestrate growth by recruiting other important proteins containing PI-4P or PI-4,5 $\mathrm{P}_{2}$ binding domains. One such example is the ADP ribosylation factor GTPase-activating protein AGD1, which is necessary for maintenance of polarity during root hair growth [15]. Membrane secretion in root hair growth is also influenced by the exocyst complex, a Rho and Rop GTPase effector, that tethers vesicles to their target membranes $[16,17]$.

Both the actin cytoskeleton and the microtubules are important during root hair growth. Cortical microtubules are oriented net axially along the fringe of the root hair tube, while endoplasmic microtubules reach from the perinuclear cytoplasm towards the tip $[6,18]$. Microtubule stabilizing or destabilizing treatments using taxol or oryzalin, respectively, lead to wavy and occasionally branched root hair phenotypes $[6,19]$. Similar phenotypes were also found in ark1 mutants lacking the functional microtubule plus-end tracking protein armadillo-repeat kinesin 1 (ARK1). ARK1 plays a key role in root hair tip growth by promoting microtubule catastrophe events [20].

In summary, while the actin cytoskeleton plays an important role as a dynamic scaffold for proper vesicle delivery in polarized root hair elongation, the microtubules are required for maintenance of cell polarity and directed growth.

\section{Root hair cell walls}

The cell wall is a dynamic structure that determines the shape of the root hair (Figure 1). Here, one can illustrate the cell wall as a corset that readily allows for expansion at the tip, but provides resistance against the turgor pressure along the shank [21]. Cellulose is a major loadbearing structure of the cell wall and is therefore the main contributor to the corset function. Two partially redundant members of the cellulose synthase (CesA)-like (CSL) superfamily, CSLD2 and CSLD3, are located at the root hair tip and are required for its growth $[22,23]$. Notably, at the growing tip of the root hair the cellulose 
microfibrils are short and randomly orientated, as revealed by ultrastructural studies [24-26]. In contrast, the shank behind the actively growing tip contains a second layer of highly ordered cellulose microfibrils oriented transversely to the axis of expansion [26-28].

Neighboring cellulose fibrils are interlinked with matrix polymers, such as hemicelluloses and pectins. Lesions in enzymes that synthesize some of these matrix polymers, for example, xyloglucans, led to root hair growth defects, perhaps due to mis-alignment of cellulose fibrils $[29,30]$. Whereas the xyloglucans thus influence root hair growth, the role of pectins is not well explored. However, pectins do have a prominent role in pollen tube growth. Here, pectin-methyl-esterases (PMEs), which de-methylesterify carboxyl residues on the pectin backbone, can affect the cell wall viscosity. Through the PME action, carboxyl residues are set free to bind $\mathrm{Ca}^{2+}$, which results in pectin cross-linking and presumably cell wall tightening at the pollen tube tip [31-34]. PME and its inhibitors, PMEIs, are, furthermore, spatio-temporally distributed along the pollen tube with a preferential activity of PMEs at the shank and PMEIs at the tip, which results in a distinct pectic composition of the pollen tube cell wall [35]. It is possible that similar distributions also may play a role in root hair growth. In addition, extensins, cell wall structural proteins, are of crucial importance for root hair development, possibly for maintaining cell wall stability. These proteins may be post-translationally modified by O-linked glycosylation, and this modification alters cell wall properties during root hair growth [36]. Recently, PFT1/MED25, a transcriptional Mediator complex subunit, was revealed to orchestrate the expression of cell wall remodelling genes including a set of peroxidases and cell wall cross-linking extensins and being required for redox homeostasis in roots and normal root hair formation [37]. These results indicate that the cell wall proteome could be a useful source to find cell wall and, therefore, tip growth modulators. However, results on the proteomic composition of root hair cell walls are scarce, not only because separating cell wall proteins from the cell wall matrix is generally challenging, but also because isolating a reasonable amount of protein from root hairs for analysis is difficult. Strategies that circumvent these problems will be major future challenges.

Not only calcium/pectin interactions but also surface ROS and $\mathrm{pH}$ are thought to directly influence cell wall viscosity of the tip surface. Hydroxyl radicals can cleave polysaccharides and thereby promote wall relaxation [38-40]. On the other hand, $\mathrm{H}_{2} \mathrm{O}_{2}$ is a substrate for peroxidases that help to stiffen the wall via crosslinking of cell wall polysaccharides [41]. This may seem like a paradox and a tight coordination between these processes is likely to occur, but how this is achieved remains unclear.

Surface $\mathrm{pH}$ may also influence the cell wall viscosity by activation of the expansins, non-hydrolytic cell wallloosening proteins, and other cell wall modifying enzymes, which promote cell wall relaxation [42-44].

\section{Who holds the reins?}

Although the molecular organization of root hair growth is described with increasing detail, how internal and environmental growth-regulating signals are sensed and integrated remains enigmatic. Nevertheless, some recent reports have begun to shed some light on this topic. In plants several receptor-like kinase (RLK) family members are implicated in relaying information about cell wall integrity (CWI) to the inside of the cell (Figure 1). These RLKs may therefore also be referred to as CWI sensors [45]. The redundant Cataranthus roseus RLK1-like subfamily members ANXUR1 (ANX1) and ANX2 are required for pollen tube growth in Arabidopsis. The ANX1 and 2 are the closest relatives to FERONIA (FER), which is essential for both pollen tube and root hair growth [46-52]. FER can affect ROS production via the regulation of Rho of plant GTPases (ROPs). ROPs accumulate in the apical plasma membrane of root hairs and other tip-growing cells, and impact actin dynamics and vesicle trafficking. For example, two counteracting Rop-interactive CRIB motif-containing (RIC) proteins control pollen tube growth by regulating Factin dynamics [53,54]. Similar effector proteins might regulate actin dynamics and vesicle trafficking in root hairs.

It is tempting to speculate that cell wall derived compounds may be putative ligands for the CWI related RLKs. This has, for example, been shown to be the case for the wallassociated kinase family that binds pectins. Furthermore, a secreted small peptide hormone, rapid alkalinisation factor (RALF) negatively regulates cell elongation by binding to the FER receptor as a ligand [55]. Against this backdrop, other small peptides may be considered as ligands for CWI related RLKs in root hair growth. While these data are encouraging, the identification of ligands for receptors is not a trivial task. The activated receptors may subsequently cause alterations in intra- and extracellular ion homeostasis, which brings us back to the $\mathrm{Ca}^{2+}$, ROS and additional signalling compounds with which we began this review.

\section{Conclusion and perspectives}

Recent undertakings have greatly improved our understanding of root hair growth (Figure 1). For example, the development of highly sophisticated calcium, $\mathrm{pH}$ and ROS sensors has revealed a tight interplay between these factors. The recent identification of several new players in the molecular synergy of root hair growth has also 
stimulated the field. Yet, many questions remain. Firstly, how are internal and external processes coordinated during root hair growth? Secondly, cell wall biosynthesis in root hair cells differs from most other cell types. But what exactly is controlling these differences? Thirdly, calcium, extracellular $\mathrm{pH}$ and ROS are important regulators of tip growth, implicated by their correlated cyclic patterns. However, the mechanisms that directly link these regulators are still largely missing, as are the identities of the ion channels that contribute to the $\mathrm{Ca}^{2+}$ uptake. Lastly, what are the CWI sensors that the tip growing cells use, how are they activated and what are they regulating? These are important factors specifying external status of the root hairs but progress in this field is still in its infancy.

Experiments aiming at answering these questions can provide us not only with new insights into how root hair growth works but might be applicable to other tip growing systems, and to elucidate general developmental patterns during cell growth.

\section{Abbreviations}

$\mathrm{ABP}$, actin binding protein; $\mathrm{ADF}$, actin depolymerizing factor; ANX1, ANXUR1; ARK1, armadillo-repeat kinesin 1; CNGC, cyclic nucleotide-gated channel; CSL, cellulose synthase-like; CWI, cell wall integrity; FER, FERONIA; GLR, glutamate receptor-like; PI, inositol phosphate; PME, pectin-methyl-esterase; PMEI, PME inhibitor; RLK, receptor-like kinase; ROP, Rho of plant GTPase; ROS, reactive oxygen species.

\section{Disclosures}

The authors declare that they have no disclosures.

\section{Acknowledgments}

We would like to thank Drs. Heather McFarlane and Clara Sanchez-Rodriguez for useful comments on the manuscript. Amelie Mendrinna and Staffan Persson were funded by the Max-Planck Gesellschaft.

\section{References}

I. Jones VA, Dolan L: The evolution of root hairs and rhizoids. Ann Bot 2012, I 10:205-12.

2. Chang F, Yan A, Zhao L, Wu W, Yang Z: A putative calciumpermeable cyclic nucleotide-gated channel, CNGC I8, regulates polarized pollen tube growth. J Integr Plant Bio 2007, 49:|26|-70.

3. Frietsch S, Wang Y, Sladek C, Poulsen LR, Romanowsky SM, Schroeder Jl, Harper JF: A cyclic nucleotide-gated channel is essential for polarized tip growth of pollen. Proc Natl Aca Sci USA 2007, 104: |453I-6.

4. Michard E, Lima PT, Borges F, Silva AC, Portes MT, Carvalho JE, Gilliham M, Liu L, Obermeyer G, Feijó JA: Glutamate receptorlike genes form $\mathrm{Ca}+$ channels in pollen tubes and are regulated by pistil D-serine. Science 201 I, 332:434-7.

\section{FlOOOPrime}

\section{RECOMMENDED}

5. Miller DD, de Ruijter NCA, Bisseling T, Emons AMC: The role of actin in root hair morphogenesis: studies with lipochito-oligosaccharide as a growth stimulator and cytochalasin as an actin perturbing drug. Plant Journal 1999, I 7:14I-54.

6. Ketelaar T, Faivre-Moskalenko C, Esseling J], de Ruijter, Norbert C A, Grierson CS, Dogterom M, Emons, Anne Mie C: Positioning of nuclei in Arabidopsis root hairs: an actin-regulated process of tip growth. Plant cell 2002, I 4:294 I-55.

\section{FIOOOPrime
RECOMMENDED}

7. Ketelaar T, de Ruijter NC, Emons AM: Unstable F-actin specifies the area and microtubule direction of cell expansion in Arabidopsis root hairs. Plant cell 2003, 15:285-92.

8. Ketelaar $\mathrm{T}$ : The actin cytoskeleton in root hairs: all is fine at the tip. Curr Opin Plant Biol 2013, I6:749-56.

9. Maciver SK, Hussey PJ: The ADF/cofilin family: actin-remodeling proteins. Genome Bio 2002, 3:reviews3007.

10. Lee YJ, Liu B: Cytoskeletal motors in Arabidopsis. Sixty-one kinesins and seventeen myosins. Plant Physiol 2004, I36:3877-83.

II. Reisen D, Hanson MR: Association of six YFP-myosin XI-tail fusions with mobile plant cell organelles. BMC Plant Bio 2007, 7:6.

12. Peremyslov VV, Prokhnevsky AI, Avisar D, Dolja VV: Two class XI myosins function in organelle trafficking and root hair development in Arabidopsis. Plant Physiol 2008, I46:I I09-16.

\section{FlOOOPrime} RECOMMENDED

13. Park E, Nebenführ A: Myosin XIK of Arabidopsis thaliana accumulates at the root hair tip and is required for fast root hair growth. PloS one 2013, 8:e76745.

\section{FlOOOPrime} RECOMMENDED

14. Preuss ML, Serna J, Falbel TG, Bednarek SY, Nielsen E: The Arabidopsis Rab GTPase RabA4b localizes to the tips of growing root hair cells. Plant Cell 2004, I6:I 589-603.

I5. Yoo C, Quan L, Cannon AE, Wen J, Blancaflor EB: AGDI, a class I ARF-GAP, acts in common signaling pathways with phosphoinositide metabolism and the actin cytoskeleton in controlling Arabidopsis root hair polarity. Plant J 2012, 69:1064-76.

16. Synek L, Schlager N, Elias M, Quentin M, Hauser MT, Zarsky V: AtEXO70AI, a member of a family of putative exocyst subunits specifically expanded in land plants, is important for polar growth and plant development. Plant J 2006, 48:54-72.

\section{FlOOOPrime}

RECOMMENDED

17. Wen T, Hochholdinger F, Sauer M, Bruce W, Schnable PS: The roothairless I gene of maize encodes a homolog of sec3, which is involved in polar exocytosis. Plant Physiol 2005, I 38: I637-43.

18. van Bruaene N, Joss G, van Oostveldt P: Reorganization and in vivo dynamics of microtubules during Arabidopsis root hair development. Plant Physiol 2004, I36:3905-19.

19. Bibikova TN, Blancaflor EB, Gilroy S: Microtubules regulate tip growth and orientation in root hairs of Arabidopsis thaliana. Plant J 1999, 1 7:657-65.

20. Eng RC, Wasteneys GO: The microtubule plus-end tracking protein ARMADILLO-REPEAT KINESIN I promotes microtubule catastrophe in Arabidopsis. Plant Cell 2014, 26:3372-86.

\section{FlOOOPrime}

RECOMMENDED

21. Cosgrove DJ: Growth of the plant cell wall. Nat Rev Mol Cell Bio 2005, 6:850-6I.

22. Park S, Szumlanski AL, Gu F, Guo F, Nielsen E: A role for CSLD3 during cell-wall synthesis in apical plasma membranes of tipgrowing root-hair cells. Nat Cell Bio 20I I, I3:973-80.

\section{FlOOOPrime}

RECOMMENDED

23. Yoo CM, Quan L, Blancaflor EB: Divergence and redundancy in CSLD2 and CSLD3 function during Arabidopsis thaliana root hair and female gametophyte development. Front Plant Sci 20 I2, 3. 
24. Newcomb EH, Bonnett HT: Cytoplasmic microtubule and wall microfibril orientation in root hairs of radish. J Cell Biol 1965, 27:575-89.

25. Galway ME, Heckman JW, Schiefelbein JW: Growth and ultrastructure of Arabidopsis root hairs: the rhd3 mutation alters vacuole enlargement and tip growth. Planta 1997, 20 I: 209-18.

26. Akkerman M, Franssen-Verheijen MA, Immerzeel $P$, Hollander $L N$, Schel JH, Emons AM: Texture of cellulose microfibrils of root hair cell walls of Arabidopsis thaliana, Medicago truncatula, and Vicia sativa. J Microsc 20I2, 247:60-7.

27. Emons AMC, Woltersarts AMC: Cortical microtubules and microfibril deposition in the cell-wall of root hairs of equisetum-hyemale. Protoplasma 1983, 1 17:68-81.

28. Emons $A M C$, Kieft $\mathrm{H}$ : Winding threads around plant cells applications of the geometrical model for microfibril deposition. Protoplasma 1994, 180:59-69.

29. Cavalier DM, Lerouxel O, Neumetzler L, Yamauchi K, Reinecke A, Freshour G, Zabotina OA, Hahn MG, Burgert I, Pauly M, Raikhel NV, Keegstra K: Disrupting two Arabidopsis thaliana xylosyltransferase genes results in plants deficient in xyloglucan, a major primary cell wall component. Plant Cell 2008, 20:1519-37.

FIOOOPRime
RECOMMENDED

30. Peña MJ, Kong Y, York WS, O'Neill MA: A galacturonic acidcontaining xyloglucan is involved in Arabidopsis root hair tip growth. Plant Cell 20I2, 24:45II-24.

\section{FlOOOPrime}

31. Willats WG, McCartney L, Mackie W, Knox JP: Pectin: cell biology and prospects for functional analysis. Plant Mol Biol 200I, 47:9-27.

32. Bosch M, Hepler PK: Pectin methylesterases and pectin dynamics in pollen tubes. Plant Cell 2005, 17:3219-26.

33. Palin $R$, Geitmann $A$ : The role of pectin in plant morphogenesis. Biosystems 2012, 109:397-402.

34. Wolf S, Greiner S: Growth control by cell wall pectins. Protoplasma 2012, 249(Suppl 2):SI69-75.

35. Röckel N, Wolf S, Kost B, Rausch T, Greiner S: Elaborate spatial patterning of cell-wall PME and PMEI at the pollen tube tip involves PMEI endocytosis, and reflects the distribution of esterified and de-esterified pectins. Plant J 2008, 53:133-43.

\section{FlOOOPrime \\ RECOMMENDED}

36. Velasquez SM, Ricardi MM, Dorosz JG, Fernandez PV, Nadra AD, PolFachin L, Egelund J, Gille S, Harholt J, Ciancia M, Verli H, Pauly M, Bacic A, Olsen CE, Ulvskov P, Petersen BL, Somerville C, lusem ND, Estevez JM: O-glycosylated cell wall proteins are essential in root hair growth. Science 20II, 332:I40I-3.

\section{FlOOOPrime}

\section{RECOMMENDED}

37. Sundaravelpandian K, Chandrika NN, Schmidt W: PFTI, a transcriptional Mediator complex subunit, controls root hair differentiation through reactive oxygen species (ROS) distribution in Arabidopsis. New Phytol 2013, 197:|5I-6I.

38. Fry SC: Oxidative scission of plant cell wall polysaccharides by ascorbate-induced hydroxyl radicals. Biochem J 1998, 332:507-I5

39. Fry SC, Dumville JC, Miller JG: Fingerprinting of polysaccharides attacked by hydroxyl radicals in vitro and in the cell walls of ripening pear fruit. Biochem J 200I, 357:729-37.

40. Schopfer P: Hydroxyl radical-induced cell-wall loosening in vitro and in vivo: implications for the control of elongation growth. Plant J 200I, 28:679-88.

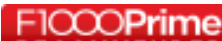

4I. Passardi F, Penel C, Dunand C: Performing the paradoxical: how plant peroxidases modify the cell wall. Trends Plant Sci 2004, 9:534-40.

42. Rayle DL, Cleland R: Enhancement of wall loosening and elongation by Acid solutions. Plant Physiol 1970, 46:250-3.

43. Cosgrove DJ: Characterization of long-term extension of isolated cell walls from growing cucumber hypocotyls. Planta 1989, I77:121-30.

44. McQueen-Mason S, Durachko DM, Cosgrove DJ: Two endogenous proteins that induce cell-wall extension in plants. Plant Cell 1992, 4: 1425.

45. Wolf $\mathrm{S}$, Hématy $\mathrm{K}$, Höfte $\mathrm{H}$ : Growth control and cell wall signaling in plants. Ann Rev Plant Biol 2012, 63:38I-407.

46. Huck N, Moore JM, Federer M, Grossniklaus U: The Arabidopsis mutant feronia disrupts the female gametophytic control of pollen tube reception. Development 2003, 130:2 149-59.

\section{FlOOOPrime}

\section{RECOMMENDED}

47. Rotman N, Rozier F, Boavida L, Dumas C, Berger F, Faure J: Female control of male gamete delivery during fertilization in Arabidopsis thaliana. Curr Bio 2003, I3:432-6.

\section{FlOOOPrime

RECOMMENDED

48. Escobar-Restrepo J, Huck N, Kessler S, Gagliardini V, Gheyselinck J, Yang W, Grossniklaus U: The FERONIA receptor-like kinase mediates male-female interactions during pollen tube reception. Science 2007, 317:656-60.

\section{FlOOOPrime}

\section{RECOMMENDED}

49. Guo H, Li L, Ye H, Yu X, Algreen A, Yin Y: Three related receptorlike kinases are required for optimal cell elongation in Arabidopsis thaliana. Proc Natl Acad Sci USA 2009, 106:7648-53.

\section{FlOOOPrime}

\section{RECOMMENDED}

50. Kessler SA, Shimosato-Asano H, Keinath NF, Wuest SE, Ingram G, Panstruga R, Grossniklaus U: Conserved molecular components for pollen tube reception and fungal invasion. Science 2010 , 330:968-71.

\section{FlOOOPrime}

RECOMMENDED

5I. Duan Q, Kita D, Li C, Cheung AY, Wu H: FERONIA receptor-like kinase regulates RHO GTPase signaling of root hair development. Proc Natl Acad Sci USA 2010, 107: 17821-6.

\section{FlOOOPrime
RECOMMENDED}

52. Duan $Q$, Kita D, Johnson EA, Aggarwal M, Gates L, Wu H, Cheung AY: Reactive oxygen species mediate pollen tube rupture to release sperm for fertilization in Arabidopsis. Nature Commun 20I4, 5:3I29.

\section{FlOOOPrime}

RECOMMENDED

53. Gu Y, Vernoud V, Fu Y, Yang Z: ROP GTPase regulation of pollen tube growth through the dynamics of tip-localized F-actin. J Exp Bot 2003, 54:93-10I.

54. Gu Y, Fu Y, Dowd P, Li S, Vernoud V, Gilroy S, Yang Z: A Rho family GTPase controls actin dynamics and tip growth via two counteracting downstream pathways in pollen tubes. J Cell Biol 2005, 169:127-38.

\section{FlOOOPrime}

RECOMMENDED

55. Haruta M, Sabat G, Stecker K, Minkoff BB, Sussman MR: A peptide hormone and its receptor protein kinase regulate plant cell expansion. Science 2014, 343:408-II. 